\title{
Prevalence of Schistosoma mansoni infection among children in Ethiopia: A systematic review and meta-analysis
}

Habtye Bisetegn ( $\square$ habtiye21@gmail.com )

Wollo University

Tegegne Eshetu

University of Gondar

Yonas Erkihun

Wollo University

\section{Research Article}

Keywords: Schistosomiasis, Schistosoma mansoni, Children and Ethiopia

Posted Date: June 1st, 2021

DOl: https://doi.org/10.21203/rs.3.rs-302779/v1

License: (1) This work is licensed under a Creative Commons Attribution 4.0 International License.

Read Full License

Version of Record: A version of this preprint was published at Tropical Diseases, Travel Medicine and Vaccines on December 1st, 2021. See the published version at https://doi.org/10.1186/s40794-02100156-0. 


\section{Abstract \\ Background}

Schistosomiasis is a neglected tropical disease caused by mainly Schistosoma mansoni and Schistosoma hematobium. The disease is very common in Africa including Ethiopia. Schistosoma mansoni is a major public health problem in Ethiopia especially among children. This review is aimed to indicate the prevalence of Schistosoma mansoni among children at national and regional level.

\section{Methods and material:}

The PRISMA guidelines were followed. Electronic search of PubMed, Google Scholar, Web of Science, Scopus, MEDLINE and Google search were carried out using key terms. Articles published from the proceeding of professional associations such as Ethiopian medical laboratory association, Ethiopian public health association and annual national research conferences were searched to find eligible studies. Data was extracted independently by two investigators, and pooled using a random effects model. Data was extracted using Microsoft excel and final analyzed using STATA version 12. Quality of included studies was assessed using JBI quality assessment criteria.

\section{Result}

Over all 41 studies involving 15968 children were included in this meta-analysis. The pooled prevalence of Schistosoma mansoni infection was 37.75\% (95\% Cl:29.97-45.53). High heterogeneity was observed with $\mathrm{I}^{2}$ of $99.3 \%, \mathrm{p}=0.000$. According to subgroup analysis, the pooled prevalence was high in SNNPR (46.27\%: 95\% Cl: $21.77-70.77)$ followed by Amhara region (41.9\%: 95\% Cl: $28.45-54.54)$ Tigray region (38.14\%: 95\%Cl:24.22-52.05) and Oromia region (26.54\%: 95\%Cl: 16.89-36.20). Year from 2011 to 2015 contribute for the highest prevalence of Schistosoma mansoni among children (44.46\% (95\%:30.8858.03).

\section{Conclusion}

This study revealed $37.75 \%$ Schistosoma mansoni infection among children. High prevalence of schistosomes among children highlights the importance of improving and implementing appropriate control strategies such as mass drug administration in Ethiopia.

\section{Introduction}

Schistosomiasis a neglected tropical parasitic disease caused by blood dwelling digenetic trematodes of the genus Schistosoma that affects mainly the poor and marginalized communities with poor sanitation and inadequate health care service [1]. Among the different Schistosoma species responsible 
schistosomiasis, the three namely S. haematobium, S. japonicum and S. mansoni impose the major public health problem [2].

Human infection occurs by skin penetration with a cercarial stage of the parasite during contact with contaminated water. The epidemiology of Schistosomiasis is characterized by a highly variable focal distribution that differs in prevalence and intensity of infection even from village to village and this is governed by the interplay of the human, snail, and human-water contact [3]. The adult Schistosomes live the host blood vessel for several years by successful evasion of the immune system, at the mean time the female worm excretes hundreds to thousands of eggs per day. The egg will either leave the body by excreta or trapped in tissue causing the main pathology of schistosomiasis [4]. Proximity to large dam reservoir, irrigation scheme, poor personal hygiene, living near open freshwater bodies and poor waste management is reported to be a risk for contraction schistosomiasis [5].

Schistosomiasis is the second widely distributed parasitic disease next to malaria with the highest morbidity and mortality [5]. It is endemic in 76 countries and territories with 200 million people being infected and 779 million people being at risk of infection worldwide $[5,6]$. About $85 \%$ of the infections occur in Africa with an estimated annual death of 280,000 people [7]. Globally schistosomiasis is responsible for 1.5 million years lived with disability (YLD) (8). The disease is very common among children with high morbidity and mortality in addition to this; it results in anemia, malnutrition, decreased aerobic capacity, growth delay, cognitive and memory impairment [4].

Approximately 207 million people required preventive treatment for schistosomiasis in 2016 worldwide. Different global and national diseases monitoring and control initiatives are ongoing to control schistosomiasis $[9,10]$. These programs are mainly based on mass drug administration (MDA) with praziquantel. Achievement is evaluated base on successful treatment of $75 \%$ school age children (SAC) $[11,12]$. Success of MDA is affected by number of children attending school and children who did not attend school at the time of MDA implementation will be excluded $[13,14]$.

In Ethiopia, Schistosomiasis is a major public health problem. In 2013 nearly 36 thousand people were infected with schistosomiasis in Ethiopia [15]. In the country, nearly 37.3 million people are at risk of infection, comprising 3.4 million pre-school children, 12.3 million school-aged children and 21.6 million adults [16]. In Ethiopia more than 14 million SAC require MDA [17]. The Federal Ministry of Health $(\mathrm{FMOH})$ of Ethiopia mapped 346 schistosomiasis endemic districts and implemented MDA through integrated training, drug distribution, mobilization, technical staff involvement and resource mobilization. In 2016 about 2.5 million SAC were targeted for MDA and 1.86 million were treated, this showed $74.4 \%$ effectiveness of the MDA program [16]. To control and eliminate schistosomiasis in Ethiopia Providing a national view of the occurrence of the disease and identifying endemic areas are highly significant. Indicating the prevalence of Schistosoma mansoni among children at national and regional level is vital for high achievement of the MDA program. It is also important to indicate the endemic areas and to know the current status of the infection. 


\section{Materials And Methods}

\section{Search strategy and selection criteria}

Systematic search of potentially eligible studies was carried out from September 01/2020 to November 31/2020 in PubMed, Google Scholar, Web of Science, Scopus, ResearchGate, MEDLINE and Google search using a combination of the key words "prevalence; magnitude; epidemiology; Schistosoma mansoni; intestinal schistosomiasis; Schistosomiasis; pre-school children; school-age children, children and Ethiopia". Articles published from the proceedings of professional associations like the Ethiopian medical laboratory association, Ethiopian public health association and annual national research conference were searched. The reference lists of the retrieved studies and reviews were further searched for additional reports.

The included studies were identified after two reviewers independently screened the title, abstract and the full-text of the articles obtained from the search and the results were cross-checked by the third reviewer. The final selection was based on the full-text evaluation.

\section{Data extraction and quality assessment}

The outcome variable for this study was prevalence of Schistosoma mansoni among children in Ethiopia.

Data were extracts by the two reviewers independently using Microsoft excel extraction sheet.

The sheet contains information including name of the primary author, year of publication, study design, diagnostic methods, study group, sample size, number of male participants, and number of female participants, number of positive cases and the region where the study was conducted.

The quality of each study was evaluated following the Joanna Briggs Institute (JBI) critical appraisal checklist for prevalence studies [18]. Studies were assessed according to the appropriateness of the method used, validity and accuracy of the diagnostic methods, adequacy of the sample size, sampling procedure, and appropriateness of the study design and the statistical analysis. Each selected study was assessed using 10 quality control items and for each item fulfilled, a score of 1 was given while a 0 was given for each unfulfilled item. An aggregate of all the scores was generated and converted into an index. Based on the quality indices generated, studies were classified as having low $(0.0-0.3)$, moderate $(0.4-$ $0.6)$ or high $(0.7-1.0)$ quality.

\section{Eligibility criteria}

The reviewers carefully screened the title, abstract and full text of each published article for its relevance, and eligibility. Original studies reporting the prevalence of Schistosoma mansoni infection among children were included in this systematic review and meta-analysis. Studies were excluded if they were reported in a language other than English, used inappropriate study design, inappropriate sample size, were conducted in a selective population, and not included relevant extractable data. Case reports, reviews, and studies conducted on adults or all ages of humans were also excluded. 


\section{Data synthesis and statistical analysis}

The pooled prevalence was calculated by using the Metan commands in STATA version 12. The pooled effect size was presented in the form of a forest plot. To account between studies variability, the metaanalysis was carried out using the random effect model. The amount of between-studies heterogeneity was quantified using $\mathrm{I}^{2}$ statistics, which describes the proportion of total variation of the effect estimates resulting from the between-studies heterogeneity and values can be from 0 up to $100 \%$. The $I^{2}$ values of $25 \%, 50 \%$, and $75 \%$ were considered low, moderate and high heterogeneity, respectively [19].

The potential influence of the covariates on the pooled effect estimate was investigated by subgroup analysis.

Subgroup analysis was done by the region where the studies were conducted, year of publication, sample size, and sex of study participants.

Publication bias was assessed by visual inspection of symmetry of the funnel plot and egger's test statistics. P-value $\leq 0.05$ and asymmetry of the funnel plot showing the presence of potential publication bias [20].

\section{Result}

\section{Selection and identification of studies}

A total of 746 articles were identified through online searching and references screening. After initial screening of the title and abstract of the identified studies, full text of potentially eligible studies was retrieved for detail assessment. A total of 681 articles were ineligible and excluded. The remaining 65 articles were assessed in detail. About 24 studies were excluded as they lack one or more variables that must be extracted for analysis leaving 41 potentially eligible studies for the final meta-analysis. Preferred Reporting Items for Systematic Review and Meta-analysis statement (PRISMA checklist 2009) was followed [21] (Fig. 1).

\section{Characteristics of included studies}

Forty-one studies involving a total of 15968 children; 8282 male and 7684 females as a study participant were included in this meta-analysis. The age of the study participants ranged from 6 month up to 18 years old. The studies were conducted from 2001 to 2020 in five national regional states of Ethiopia. Nineteen of the studies were in Amhara region, 10 in Oromia region, 6 in Southern Nation Nationalities and people Region (SNNPR), 5 in Tigray region and 1 in Somali region of Ethiopia. All the included studies had a cross-sectional design and had estimated point prevalence. The sample size of the studies ranged from 150 to 689. Majority of the studies used Kato Katz thick smear as a diagnostic method (Table 1). 
Table 1

Characteristics of included studies

\begin{tabular}{|c|c|c|c|c|c|}
\hline Author/reference & Year & Region & $\begin{array}{l}\text { Sample } \\
\text { size }\end{array}$ & Diagnostic methods & Prevalence \\
\hline $\begin{array}{l}\text { Tiruneh A et al } \\
\text { [22] }\end{array}$ & 2020 & SNNPR & 389 & Kato-Katz thick smear & 19.3 \\
\hline Alemu A et al [23] & 2011 & Amhara & 319 & Kato-Katz thick smear & 37.9 \\
\hline Alemu A et al[24] & 2016 & Amhara & 401 & Kato-Katz thick smear & 11.2 \\
\hline $\begin{array}{l}\text { Assefa A et al } \\
\text { [25] }\end{array}$ & 2013 & Tigray & 457 & Kato-Katz thick smear & 23.9 \\
\hline Tefera A et al[26] & 2020 & Oromia & 328 & Kato-Katz thick smear & 28.7 \\
\hline $\begin{array}{l}\text { Tadege B et al } \\
\text { [27] }\end{array}$ & 2017 & SNNPR & 384 & Kato-Katz thick smear & 31 \\
\hline $\begin{array}{l}\text { Alemayehu B et } \\
\text { al[28] }\end{array}$ & 2015 & SNNPR & 384 & Kato-Katz thick smear & 81.3 \\
\hline $\begin{array}{l}\text { Alemayehu B et } \\
\text { al [29] }\end{array}$ & 2017 & SNNPR & 503 & Kato-Katz thick smear & 58.6 \\
\hline $\begin{array}{l}\text { Mathewos B et al } \\
\text { [30] }\end{array}$ & 2014 & Amhara & 261 & Kato-Katz thick smear & 33.7 \\
\hline Feleke D et al [31] & 2017 & Amhara & 279 & $\begin{array}{l}\text { Formol-Ether concentration and } \\
\text { direct wet mount }\end{array}$ & 80.5 \\
\hline $\begin{array}{l}\text { Gashaw F et al } \\
\text { [32] }\end{array}$ & 2015 & Amhara & 550 & Kato-Katz thick smear & 49 \\
\hline $\begin{array}{l}\text { Amsalu G et al } \\
\text { [33] }\end{array}$ & 2015 & Amhara & 380 & Kato-Katz thick smear & 45 \\
\hline Alebie G et al [34] & 2014 & Amhara & 384 & Kato-Katz thick smear & 82.8 \\
\hline Desta $\mathrm{H}$ et al [35] & 2014 & Tigray & 469 & Kato-Katz thick smear & 42.4 \\
\hline Wubet K et al [36] & 2020 & Amhara & 362 & Formol-Ether concentration & 15.2 \\
\hline $\begin{array}{l}\text { Workineh L et al } \\
\text { [37] }\end{array}$ & 2019 & Amhara & 422 & Kato-Katz thick smear & 24.9 \\
\hline Worku L et al [38] & 2014 & Amhara & 385 & $\begin{array}{l}\text { Kato-Katz thick smear and Formol- } \\
\text { Ether concentration }\end{array}$ & 89.9 \\
\hline $\begin{array}{l}\text { Alemu M et al } \\
\text { [39] }\end{array}$ & 2014 & SNNPR & 405 & Kato-Katz thick smear & 12.6 \\
\hline Bajiro M et al [40] & 2017 & Oromia & 500 & Kato-Katz thick smear & 27.6 \\
\hline Bajiro M et al[41] & 2018 & Oromia & 233 & Kato-Katz thick smear & 26.6 \\
\hline
\end{tabular}




\begin{tabular}{|c|c|c|c|c|c|}
\hline Author/reference & Year & Region & $\begin{array}{l}\text { Sample } \\
\text { size }\end{array}$ & Diagnostic methods & Prevalence \\
\hline $\begin{array}{l}\text { Ansha M et al } \\
\text { [42] }\end{array}$ & 2020 & Oromia & 298 & Kato-Katz thick smear & 11.4 \\
\hline Hailu T et al[43] & 2018 & Amhara & 409 & Ritchie's concentration & 13.7 \\
\hline $\begin{array}{l}\text { Ibrahim T et al } \\
\text { [44] }\end{array}$ & 2018 & Oromia & 340 & Kato-Katz thick smear & 12.94 \\
\hline $\begin{array}{l}\text { Bekana T et al } \\
\text { [45] }\end{array}$ & 2019 & Oromia & 317 & Kato-Katz thick smear & 42.9 \\
\hline $\begin{array}{l}\text { Teshale T et al } \\
\text { [46] }\end{array}$ & 2018 & Tigray & 410 & Kato-Katz thick smear & 38.5 \\
\hline $\begin{array}{l}\text { Teklemariam A et } \\
\text { al[47] }\end{array}$ & 2014 & Tigray & 480 & Formol-ether concentration & 23.13 \\
\hline Fentie T et al [48] & 2013 & Amhara & 520 & Kato-Katz thick smear & 16.7 \\
\hline Mitiku H et al[49] & 2010 & Oromia & 375 & Kato-Katz thick smear & 12 \\
\hline $\begin{array}{l}\text { Legesse L et al } \\
\text { [50] }\end{array}$ & 2010 & Tigray & 381 & $\begin{array}{l}\text { Kato-Katz thick smear and Formol- } \\
\text { Ether concentration }\end{array}$ & 63 \\
\hline $\begin{array}{l}\text { Jemaneh L et al } \\
\text { [51] }\end{array}$ & 2001 & Amhara & 687 & Kato-Katz thick smear & 19.4 \\
\hline $\begin{array}{l}\text { Endris } \mathrm{M} \text { et al } \\
\text { [52] }\end{array}$ & 2010 & Amhara & 354 & Kato-Katz thick smear & 43.5 \\
\hline Essa T el al [53] & 2013 & Amhara & 579 & Kato-Katz thick smear & 20.6 \\
\hline $\begin{array}{l}\text { Addisu T et al } \\
\text { [54] }\end{array}$ & 2015 & Amhara & 365 & Kato-Katz thick smear & 15.9 \\
\hline Tulu B et al [55] & 2014 & Oromia & 340 & Formol-Ether concentration & 12.6 \\
\hline $\begin{array}{l}\text { Kemal M et al } \\
\text { [56] }\end{array}$ & 2019 & Somali & 236 & Kato-Katz thick smear & 25 \\
\hline Bajiro M et al[57] & 2016 & Oromia & 500 & Kato-Katz thick smear & 24 \\
\hline Reta B et al [58] & 2013 & Amhara & 342 & Kato-Katz thick smear & 70.47 \\
\hline Erko B et al [59] & 2012 & SNNPR & 299 & Kato-Katz thick smear & 74.9 \\
\hline Haile S et al [60] & 2012 & Oromia & 324 & Kato-Katz thick smear & 67.6 \\
\hline $\begin{array}{l}\text { Woldegerima E et } \\
\text { al [61] }\end{array}$ & 2018 & Amhara & 372 & Kato-Katz thick smear & 35 \\
\hline Tesfie A et al [62] & 2020 & Amhara & 245 & Kato-Katz thick smear & 83.3 \\
\hline
\end{tabular}

Prevalence of Schistosoma mansoni among children in Ethiopia 
The prevalence of Schistosoma mansoni infection among children in the included studies ranged from 11.4\% reported in Oromia region by Ansha M. et al, 2020 [42] to 89.9\% reported from Amhara region by Worku L. et a/ 2014 [38]. This meta-analysis showed pooled prevalence of Schistosoma mansoni infection among children as $37.75 \%$ (95\% Cl:29.97-45.53) using random effect model. High heterogeneity was observed across the included studies with $\mathrm{I}^{2}$ value of $99.3 \%, \mathrm{p}=0.000$ (Fig. 2).

\section{Subgroup analysis}

Subgroup analysis was conducted by sex, categorized sample size, publication year and the region where the studies were conducted. According to the region, the highest pooled prevalence of Schistosoma mansoni infection among children was from SNNPR $(46.27 \%, 95 \% \mathrm{Cl}$ : $21.77-70.77)$ followed by Amhara region (41.9\%, 95\% Cl: $28.45-54.54)$, Tigray region (38.14\%, 95\% Cl: $24.22-52.05)$ and Oromia region (26.54\%, 95\% Cl: $16.89-36.20)$. According to publication year of the included studies, the highest pooled prevalence of Schistosoma mansoni infection was observed in studies conducted from 2011 to 2015 (44.46\%, 95\%:30.88-58.03) followed by 2006 to 2010 (39.46, 95\%Cl: 7.58-71.34) and 2016 to 2020 (32.09\%, 95\% Cl: $22.84-41.34)$. The pooled prevalence was higher among studies that have a sample size less than or equal to the average sample size compared to those that have sample size greater than the average sample size (43.93\% vs $27.01 \%$ ) (Table 2$)$. The pooled prevalence was higher in males $(37.73 \%$, 95\%Cl: 29.77-45.68) (Fig. 3) compared to females (30.76\%, 95\% Cl, 23.40-38.11) (Fig. 4). 
Table 2

Prevalence of Schistosoma mansoni infection among children in Ethiopia by subgroups.

\begin{tabular}{|c|c|c|c|c|c|}
\hline Variable & Characteristics & $\begin{array}{l}\text { Number of } \\
\text { studies }\end{array}$ & $\begin{array}{l}\text { Sample } \\
\text { size }\end{array}$ & Prevalence & $\begin{array}{l}\mathrm{I}^{2}, \mathrm{p} \\
\text { value }\end{array}$ \\
\hline \multirow[t]{4}{*}{ Region } & SNNPR & 6 & 2,364 & $\begin{array}{l}46.27 \% \text { (95\%Cl: } 21.77- \\
70.77)\end{array}$ & $\begin{array}{l}99.5 \%, \\
0.00\end{array}$ \\
\hline & Amhara & 19 & 7,616 & $\begin{array}{l}41.9 \% \text { (95Cl: } 28.45- \\
54.54)\end{array}$ & $\begin{array}{l}99.5 \%, \\
0.00\end{array}$ \\
\hline & Tigray & 5 & 2,197 & $\begin{array}{l}38.14 \%(95 \% \mathrm{Cl}: 24.22- \\
52.05)\end{array}$ & $\begin{array}{l}98.1 \%, \\
0.00\end{array}$ \\
\hline & Oromia & 10 & 3,555 & $\begin{array}{l}26.54 \%,(95 \% \mathrm{Cl}: 16.89- \\
36.20)\end{array}$ & $\begin{array}{l}98.2 \% \\
0.00\end{array}$ \\
\hline \multirow[t]{2}{*}{ Sample size } & $\leq 390$ & 26 & 8,676 & $\begin{array}{l}43.93 \% \text { (95\%Cl: } 32.47- \\
55.40)\end{array}$ & $\begin{array}{l}99.5 \%, \\
0.00\end{array}$ \\
\hline & $>390$ & 15 & 7,297 & $\begin{array}{l}27.01 \% \text { (95\%Cl: } 20.47- \\
33.56)\end{array}$ & $\begin{array}{l}97.9 \%, \\
0.00\end{array}$ \\
\hline \multirow[t]{4}{*}{$\begin{array}{l}\text { Publication } \\
\text { year }\end{array}$} & 2001 to 2005 & 1 & 687 & $\begin{array}{l}19.4 \%(95 \% \mathrm{Cl}: 16.44- \\
22.36)\end{array}$ & - \\
\hline & 2006 to 2010 & 3 & 1,110 & $\begin{array}{l}39.46 \text { (95\%Cl: } 7.58- \\
71.34)\end{array}$ & $\begin{array}{l}99.4 \%, \\
0.00\end{array}$ \\
\hline & 2011 to 2015 & 18 & 7,243 & $\begin{array}{l}44.46 \%(95 \%: 30.88- \\
58.03)\end{array}$ & $\begin{array}{l}99.5 \%, \\
0.00\end{array}$ \\
\hline & 2016 to 2020 & 19 & 6,928 & $\begin{array}{l}32.09 \%(95 \% \mathrm{Cl}: 22.84- \\
41.34)\end{array}$ & $\begin{array}{l}98.9 \%, \\
0.00\end{array}$ \\
\hline
\end{tabular}

\section{Publication bias}

The publication bias was assessed by visual inspection of the funnel plot and using egger's test statistics. Logit of proportion and its standard error were used to evaluate the presence or absence of bias. The result showed the absence of publication bias with p-value of 0.582 .

\section{Discussion}

Schistosoma mansoni infection continued to be a major public health problem world-wide especially among children who are expected to have frequent water contact with 200 million cases [63]. To our knowledge, this study is the first comprehensive systematic review and meta-analysis of primary studies to indicate the prevalence of Schistosoma mansoni infection among children at national level. We performed compressive review and meta-analyses of 41 cross-sectional studies reporting the prevalence of schistoma mansoni infection among children in Ethiopia. Ethiopia is continuously implementing the MDA program with large scale periodic treatment since 2010 to reduce the burden of schistosomiasis and other intestinal parasitic infections. The country had also planned to reduce the national prevalence 
of schistosomiasis below one percent [16]. However, this systematic review and meta-analysis showed the pool prevalence of Schistosoma mansoni infection among children as $37.75 \%$ (95\%Cl: $29.97-45.53)$. This result indicates as schistosomiasis being still a public health problem among children in Ethiopia. High between study heterogeneity was noted with $1^{2}$ value of $99.3 \%$. In order to account this heterogeneity, subgroup analysis was done according to sex, sample size, year of publication and by regions where the studies were conducted. According to subgroup analysis the pooled estimate of Schistosoma mansoni prevalence was found to be higher among male children than females $(37.73 \%$ vs $3076 \%$ ). The high prevalence in male might be due to high swing activity of males than females, outdoor activities of male children in rural areas than females.

The pooled prevalence of Schistosoma mansoni infection among children was highest in SNNPR 46.27\% (95\%Cl: $21.77-70.77)$ followed by Amhara region $41.9 \%$, (95\% Cl: $28.45-54.54)$, Tigray region $38.14 \%$, (95\%Cl: $24.22-52.05)$ and Oromia regional state $26.54 \%$, (95\% Cl: $16.89-36.20)$. This variation may be due to the difference in implementation of the mass drug administration program, difference in efficacy of praziquantel, behavioral activities, environmental and personal sanitation, epidemiology of the snail vector, habit of open defecation, utilization of night soil as a fertilized and the geographical difference. The other explanation may be the SNNPR are rich in water bodies which can be favorable for the intermediate snail species. The pooled estimate was found to be high in studies conducted 2011 to 2015 (44.46\%, 95\%: Cl: 30.88-58.03) followed by 2006 to 010 (39.46\%, 95\%Cl: 7.58-71.34) and 2016 to 2020 (32.09\% 95\% Cl: 22.84-41.34). The reduced prevalence from 2016 to 2020 might be due to implementation, monitoring and evaluation of the schistosomiasis control program such as mass drug administration program in school. High coverage of the mass drug administration which mainly focus on school children. In addition, it might be due to awareness creation in the community about keeping sanitation and hygiene of water bodies.

The studies were group as studies having above and below the average sample size (the average sample size was 390$)$. The pooled prevalence was $43.93 \%,(95 \% \mathrm{Cl}: 32.47-55.40)$ in studies with sample size of $\leq 390$ and $27.01 \%$ (95\% Cl: 20.47-33.56) in studies with sample size $>390$. The between studies heterogeneity remained high even after subgroups analysis. The symmetry of funnel plot and the statistical analysis with the egger's test statistics ruled out the absence of publication bias with $p$ value of 0.582. Our study has limitations such as; between-study heterogeneity among enrolled studies was remarkable. We did not assess the factors that associated with the prevalence of Schistosoma mansoni infection.

\section{Conclusion And Recommendation}

This meta-analysis summarized a high prevalence of Schistosoma mansoni among children in Ethiopia, suggesting as Schistosoma mansoni infection in a major public health problem in the country. The pooled prevalence of the infection is highest in SNNPR. Males were more affected than females. This systematic review identified a wide range of the prevalence of Schistosoma mansoni among children in Ethiopia from 2001 to 2020. To eliminate/control schistosomiasis in the country, the Ethiopian Federal 
Ministry of Health should work with different stakeholders and recognize Schistosoma mansoni infection as a major health problem in the country, design cost effective monitoring and control programs, increases the geographical coverage of MDA and improve the delivery of the drug to the MDA sites.

\section{Abbreviations}

MDA

Mass Drug Administration

SAC

School Age Children

SNNPR

Southern Nation Nationalities and People's Region.

\section{Declarations}

\section{Author's contribution}

Habtye B designed the study and wrote the protocol. Yonas E, Habtye B and Tegegne E did the systematic review. Habtye $B$ did the statistical analysis. Habtye $B$ wrote the frist draft, which was critically revised by Yonas $\mathrm{E}$ and Tegegne $\mathrm{E}$. All authors commented on the drafts and approved the final version.

\section{Competing interests}

The authors declared no competing interests.

\section{Acknowledgments}

The authors of this systematic review would like to acknowledge the all the authors of the included studies and friends who participate in searching of the articles.

\section{Funding source}

There is no specific funding for this systematic review and meta-analysis.

\section{Availability of data}

All the necessary materials are available within the manuscript.

\section{Consent for publication}

Not applicable.

\section{Ethical approval and consent to participate}


Since this study is systematic review and meta-analysis and does not involve human and animal studies, Ethical approval and consent to participate are not applicable.

\section{Author details}

${ }^{1}$ College of medicine and Health sciences, Department of Medical Laboratory Sciences, Dessie, Ethiopia,

${ }^{2}$ College of Medicine and Health Sciences, School of Biomedical and Laboratory Sciences, Department of Medical Parasitology, University of Gondar, Gondar, Ethiopia.

\section{References}

1. Mackey TK, Liang BA, Cuomo R, Hafen R, Brouwer KC, Lee DE. Emerging and reemerging neglected tropical diseases: a review of key characteristics, risk factors, and the policy and innovation environment. Clinical microbiology review. 2014;27(4):949-79.

2. Stefanie Knopp SL, Becker KJ, Ingram J, Keiser J, Utzinger. Diagnosis and treatment of schistosomiasis in children in the era of intensified control. Expert Rev Anti Infect. 2013.

3. Donald P, McManus DW, Dunne M, Sacko J, Utzinger BJ. Vennervald, Xiao-Nong Zhou. Schistosomiasis. Nature Reviews Disease Primers. 2018;4:13.

4. Colley DG, Bustinduy AL, Secor WE, King CH. Human schistosomiasis. The Lancet. 2014;383(9936):2253-64.

5. Steinmann P, Keiser J, Bos R, Tanner M, Utzinger J. Schistosomiasis and water resources development: systematic review, meta-analysis, and estimates of people at risk. Lancet Infect Dis. 2006;6(7):411-25.

6. WHO. Schistosomiasis and soil transmitted helminthiases: numbers of people treated in 2018. Wkly Epidemiol Rec. 2019;94:601-12.

7. World health Organization. Weekly epidemiological record. WHO. 2010;85(15):157-64.

8. GBD 2016 Disease and Injury Incidence and Prevalence Collaborators. Global, regional, and national incidence, prevalence, and years lived with disability for 328 diseases and injuries for 195 countries, 1990-2016: a systematic analysis for the Global Burden of Disease Study. Lancet. 2017;390:121159.

9. Lorenzo Savioli M, Albonico DG, Colley R, Correa-Oliveira A, Fenwick W, Green, et al. Building a global schistosomiasis alliance: an opportunity to join forces to fight inequality and rural poverty. Infectious Diseases of Poverty. 2017;6(1):65-70.

10. Fenwick Webster A, Bosque-oliva JP, Blair EL, Fleming FM, Zhang Y, et al. The Schistosomiasis Control Initiative (SCI): rationale, development and implementation from 2002-2008. Parasitology. 2009;136(13):1719-30.

11. Savioli L, Gabrielli AF, Montresor A, Chitsulo L, Engels D. Schistosomiasis control in Africa: 8 years after World Health Assembly Resolution 54.19. Parasitology. 2009;136(13):1677-81. 
12. WHO. Schistosomiasis: progress report 2001-2011 strategic plan 2012-2020. Geneva: World Health Organization. 2013;9241503173.

13. Olsen A. Experience with school-based interventions against soil-transmitted helminths and extension of coverage to non-enrolled children. Acta Trop. 2003;86(2-3):255-66.

14. Talaat M, Omar M, Evans D. Developing strategies to control schistosomiasis morbidity in nonenrolled school-age children: experience from Egypt. Tropical Med Int Health. 1999;4(8):555-6.

15. Federal Democratic Republic of Ethiopia Ministry of Health. Second Edition of Ethiopia National Master Plan For Neglected Tropical Diseases. Addis Ababa, Ethiopia. 2016.

16. Nebiyu Negussu B, Mengistu B, Kebede K, Deribe E, Ejigu G, Tadesse, et al. Ethiopia Schistosomiasis and Soil-Transmitted Helminthes Control Programme: Progress and Prospects. Ethiop Med J. 2017;55(1):75-80.

17. Leta GT, Mekete K, Wuletaw Y, Gebretsadik A, Sime H, Mekasha S, et al. National mapping of soiltransmitted helminth and schistosome infections in Ethiopia. Parasites Vectors. 2020;13(1):437.

18. Munn Z, Moola S, Lisy K, Riitano D, Tufanaru C. Methodological guidance for systematic reviews of observational epidemiological studies reporting prevalence and cumulative incidence data. JBI Evidence Implementation. 2015;13(3):147-53.

19. Higgins JPT, Thompson SG. Quantifying heterogeneity in a meta-analysis. Statist Med. 2002;21(11):1539-58.

20. Tang J-L, Liu JL. Misleading funnel plot for detection of bias in meta-analysis. J Clin Epidemiol. 2000;53(5):477-84.

21. Moher D, Liberati A, Tetzlaff J, Altman DG, PRISMA Group. Preferred reporting items for systematic reviews and meta-analyses: the PRISMA statement. Ann Intern Med. 2009;151(4):264-9. W64.

22. Tiruneh A, Kahase D, Zemene E, Tekalign E, Solomon A, Mekonnen Z. Identification of transmission foci of Schistosoma mansoni: narrowing the intervention target from district to transmission focus in Ethiopia. BMC Public Health. 2020;20(1):769.

23. Alemu A, Atnafu A, Addis Z, Shiferaw Y, Teklu T, Mathewos B, et al. Soil transmitted helminths and schistosoma mansoni infections among school children in zarima town, northwest Ethiopia. BMC Infect Dis. 2011;11(1):189.

24. Alemu A, Tegegne Y, Damte D, Melku M. Schistosoma mansoni and soil-transmitted helminths among preschool-aged children in Chuahit, Dembia district, Northwest Ethiopia: prevalence, intensity of infection and associated risk factors. BMC Public Health. 2016;16(1):422.

25. Alembrhan Assefa T, Dejenie Z, Tomass. Infection prevalence of Schistosoma mansoni and associated risk factors among schoolchildren in suburbs of Mekelle city, Tigray. Northern Ethiopia MEJS. 2013;5(1):174-88.

26. Tefera A, Belay T, Bajiro M. Epidemiology of Schistosoma mansoni infection and associated risk factors among school children attending primary schools nearby rivers in Jimma town, an urban setting, Southwest Ethiopia. Diemert DJ, editor. PLoS ONE. 2020;15(2):e0228007. 
27. Tadege B, Shimelis T. Infections with Schistosoma mansoni and geohelminths among school children dwelling along the shore of the Lake Hawassa, southern Ethiopia. Deribe K, editor. PLoS ONE. 2017;12(7):e0181547.

28. Alemayehu B, Tomass Z. Schistosoma mansoni infection prevalence and associated risk factors among schoolchildren in Demba Girara, Damot Woide District of Wolaita Zone, Southern Ethiopia. Asian Pacific Journal of Tropical Medicine. 2015 Jun [cited 202;8(6):457-63.

29. Alemayehu B, Tomass Z, Wadilo F, Leja D, Liang S, Erko B. Epidemiology of intestinal helminthiasis among school children with emphasis on Schistosoma mansoni infection in Wolaita zone, Southern Ethiopia. BMC Public Health. 2017;17(1):587.

30. Mathewos B, Alemu A, Woldeyohannes D, Alemu A, Addis Z, Tiruneh M, et al. Current status of soil transmitted helminths and Schistosoma mansoni infection among children in two primary schools in North Gondar, Northwest Ethiopia: a cross sectional study. BMC Res Notes. 2014;7(1):88.

31. Feleke DG, Arega S, Tekleweini M, Kindie K, Gedefie A. Schistosoma mansoni and other helminthes infections at Haike primary school children, North-East, Ethiopia: a cross-sectional study. BMC Res Notes. 2017;10(1):609.

32. Gashaw F, Aemero M, Legesse M, Petros B, Teklehaimanot T, Medhin G, et al. Prevalence of intestinal helminth infection among school children in Maksegnit and Enfranz Towns, northwestern Ethiopia, with emphasis on Schistosoma mansoni infection. Parasites Vectors [Internet]. 2015 Dec [cited 2020 Sep 15];8(1):567.

33. Amsalu G, Mekonnen Z, Erko B. A new focus of schistosomiasis mansoni in Hayk town, northeastern Ethiopia. BMC Res Notes. 2015;8(1):22.

34. Alebie G, Erko B, Aemero M, Petros B. Epidemiological study on Schistosoma mansoni infection in Sanja area, Amhara region. Ethiopia Parasit Vectors. 2014;7(1):15.

35. Desta H, Bugssa G. The Current Status of Schistosoma mansoni Infection among School Children around Hizaty Wedicheber Microdam in Merebmieti, Ethiopia. J Bacteriol Parasitol. 2014;5(5).

36. Wubet K, Damtie D. Prevalence of Schistosoma mansoni Infection and Associated Risk Factors among School Children in Jiga Town, Northwest-Ethiopia: A Cross-Sectional Study. Journal of Parasitology Research. 2020:1-7.

37. Workineh L, Yimer M, Gelaye W, Muleta D. The magnitude of Schistosoma mansoni and its associated risk factors among Sebatamit primary school children, rural Bahir Dar, Northwest Ethiopia: a cross-sectional study. BMC Res Notes. 2019;12(1):447.

38. Worku L, Damte D, Endris M, Tesfa H, Aemero M. Schistosoma mansoni Infection and Associated Determinant Factors among School Children in Sanja Town, Northwest Ethiopia. Journal of Parasitology Research. 2014:1-7.

39. Alemu M. Prevalence of Intestinal Schistosomiasis and Soil Transmitted Helminthiasis among Primary School Children in Umolante District, South Ethiopia. CMR. 2014;3(6):174.

40. Bajiro M, Dana D, Levecke B. Prevalence and intensity of Schistosoma mansoni infections among schoolchildren attending primary schools in an urban setting in Southwest, Ethiopia. BMC Res Notes. 
2017;10(1):677.

41. Mitiku Bajiro S, Gedamu N, Hamba YonasAlemu. Prevalence. Intensity of Infection and Associated Risk Factors for Schistosoma mansoni and Soil Transmitted Helminthes among Two Primary School Children at nearby Rivers in Jimma Town, South West Ethiopia. Ann Clin Pathol. 2018;6(4):1144-51.

42. Ansha MG, Kuti KA, Girma E. Prevalence of Intestinal Schistosomiasis and Associated Factors among School Children in Wondo District, Ethiopia. Journal of Tropical Medicine;2020:1-8.

43. Hailu T, Alemu M, Abera B, Mulu W, Yizengaw E, Genanew A, et al. Multivariate analysis of factors associated with Schistosoma mansoni and hookworm infection among primary school children in rural Bahir Dar, Northwest Ethiopia. Trop Dis Travel Med Vaccines. 2018;4(1).

44. Temam Ibrahim E, Zemene Y, Asres D, Seyoum A, Tiruneh L, Gedefaw, et al. Epidemiology of soiltransmitted helminths and Schistosoma mansoni: a base-line survey among school children, Ejaji, Ethiopia. J Infect Dev Ctries. 2018;12(12):1134-44.

45. Bekana T, Hu W, Liang S, Erko B. Transmission of Schistosoma mansoni in Yachi areas, southwestern Ethiopia: new foci. Infect Dis Poverty. 2019;8(1):1.

46. Teshale T, Belay S, Tadesse D, Awala A, Teklay G. Prevalence of intestinal helminths and associated factors among school children of Medebay Zana wereda; North Western Tigray, Ethiopia 2017. BMC Res Notes. 2018;11(1):444.

47. Teklemariam D, Legesse M, Degarege A, Liang S, Erko B. Schistosoma mansoni and other intestinal parasitic infections in schoolchildren and vervet monkeys in Lake Ziway area, Ethiopia. BMC Res Notes. 2018;11(1):146.

48. Tsegaw Fentie S, Erqou M, Gedefaw A, Desta. Epidemiology of human fascioliasis and intestinal parasitosis among schoolchildren in Lake Tana Basin, northwest Ethiopia. Trans R Soc Trop Med Hyg. 2013;107:480-6.

49. Habtamu Mitiku M, Legesse Z, Teklemariam, Berhanu Erko. Transmission of Schistosoma mansoni in Tikur Wuha area, Southern Ethiopia. Ethiop J Health Dev. 2010;24(3):180-4.

50. Lemlem Legesse B, Erko A, Hailu. Current status of intestinal Schistosomiasis and soiltransmitted helminthiasis among primary school children in Adwa Town, Northern Ethiopia. Ethiop J Health Dev. 2010;24(3):191-7.

51. Leykun Jemaneh. Soil-Transmitted Helminth Infections and Schistosomiasis mansoni in School Children from Chilga District, Northwest Ethiopia. Ethiop J Health Sci. 2001;11(2):79-87.

52. Mengistu Endris W, Lemma Y, Belyhun B, Moges A, Gelaw B, Anagaw, et al. Prevalence of intestinal parasites and associated risk factors among students of Atse fasil general elementary school Azezo, Northwest Ethiopia. Ethiop J Health Biomed Sci. 2010;3(1):25-33.

53. Essa T, Birhane Y, Endris M, Moges A, Moges F. Current Status of Schistosoma mansoni Infections and Associated Risk Factors among Students in Gorgora Town, Northwest Ethiopia. ISRN Infectious Diseases. 2013:1-7.

54. Addisu T, Asmamaw A. A Survey of Soil-Transmitted Helminths Infections and Schistosomiasis mansoni among School Children in Libo-Kemkem District, Northwest Ethiopia: Cross Sectional Study. 
American Journal of Health Research. 2015;3(2):57-62.

55. Begna Tulu S, Taye E, Amsalu. Prevalence and its associated risk factors of intestinal parasitic infections among Yadot primary school children of South Eastern Ethiopia: a cross-sectional study. BMC Research Notes. 2014;7:848-54.

56. Kemal M, Tadesse G, Esmael A, Abay SM, Kebede T. Schistosoma mansoni infection among preschool age children attending Erer Health Center, Ethiopia and the response rate to praziquantel. BMC Res Notes. 2019;12(1):211.

57. Bajiro M, Dana D, Ayana M, Emana D, Mekonnen Z, Zawdie B, et al. Prevalence of Schistosoma mansoni infection and the therapeutic efficacy of praziquantel among school children in Manna District, Jimma Zone, southwest Ethiopia. Parasites Vectors. 2016;9(1):560.

58. Reta B, Erko B. Efficacy and side effects of praziquantel in the treatment for Schistosoma mansoni infection in school children in Senbete Town, northeastern Ethiopia. Trop Med Int Health. 2013;18(11):1338-43.

59. Erko B, Degarege A, Tadesse K, Mathiwos A, Legesse M. Efficacy and side effects of praziquantel in the treatment of Schistosomiasis mansoni in schoolchildren in Shesha Kekele Elementary School, Wondo Genet, Southern Ethiopia. Asian Pacific Journal of Tropical Biomedicine. 2012;2(3):235-9.

60. Haile S, * Golassa L. Zeleke Mekonnen. Prevalence of Schistosoma mansoni and effectiveness of Praziquantel in school children in Finchaa valley, Ethiopia. Journal of Parasitology and Vector Biology. 2012;4(3):25-30.

61. Woldegerima E, Bayih AG, Tegegne Y, Aemero M, Jejaw Zeleke A. Prevalence and Reinfection Rates of Schistosoma mansoni and Praziquantel Efficacy against the Parasite among Primary School Children in Sanja Town, Northwest Ethiopia. Journal of Parasitology Research. 2019:1-8.

62. Tesfie A, Getnet G, Abere A, Yihenew G, Belete Y, Kassa M, et al. Praziquantel is an effective drug for the treatment of Schistosoma Mansoni infection among school-aged children in Northwest Ethiopia. Trop Med Health. 2020;48(1):28.

63. Chitsulo L, Engels D, Montresor A, Savioli L. The global status of schistosomiasis and its control. Acta Trop. 2000;77(1):41-5.

\section{Figures}



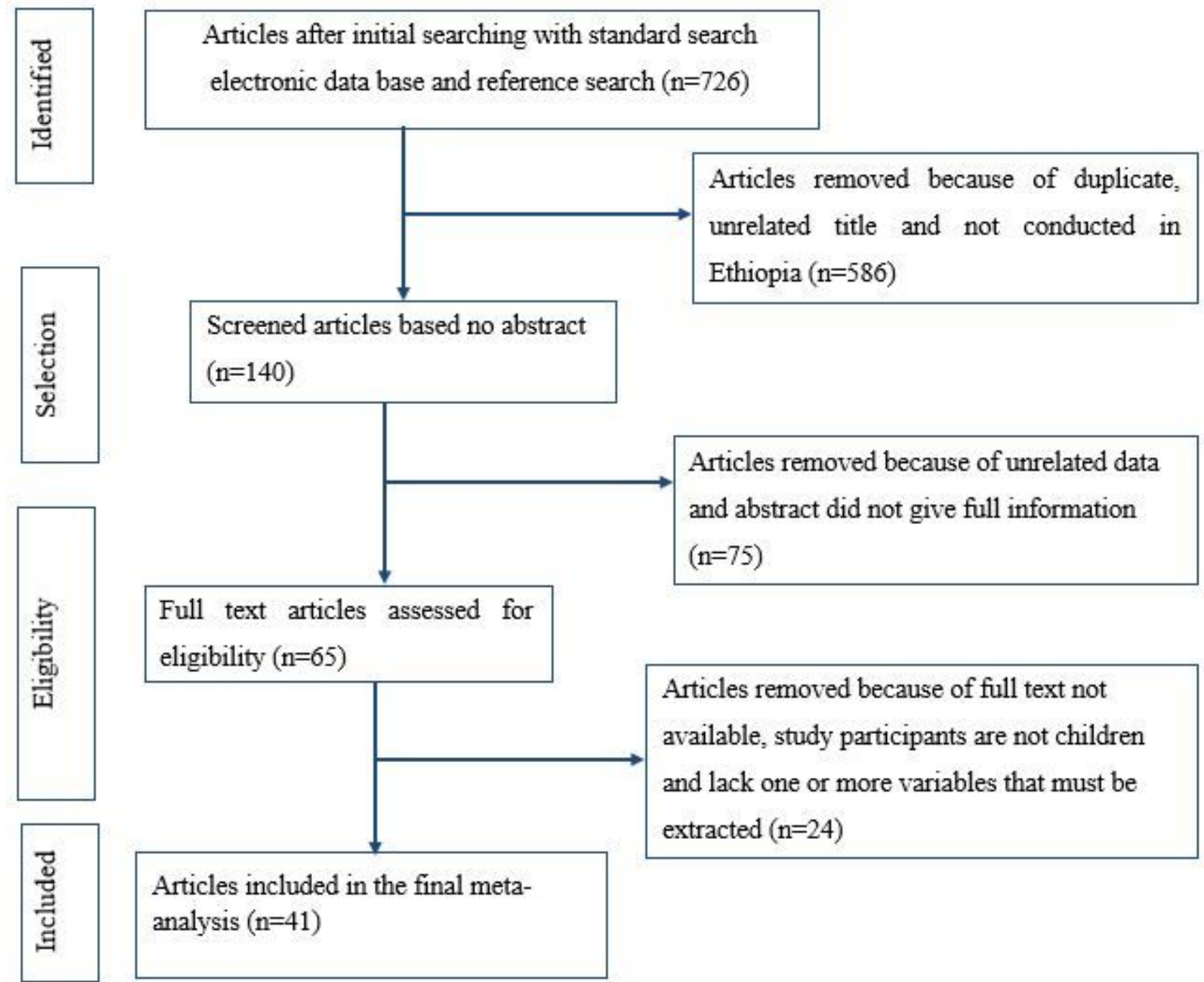

Screened articles based no abstract $(n=140)$
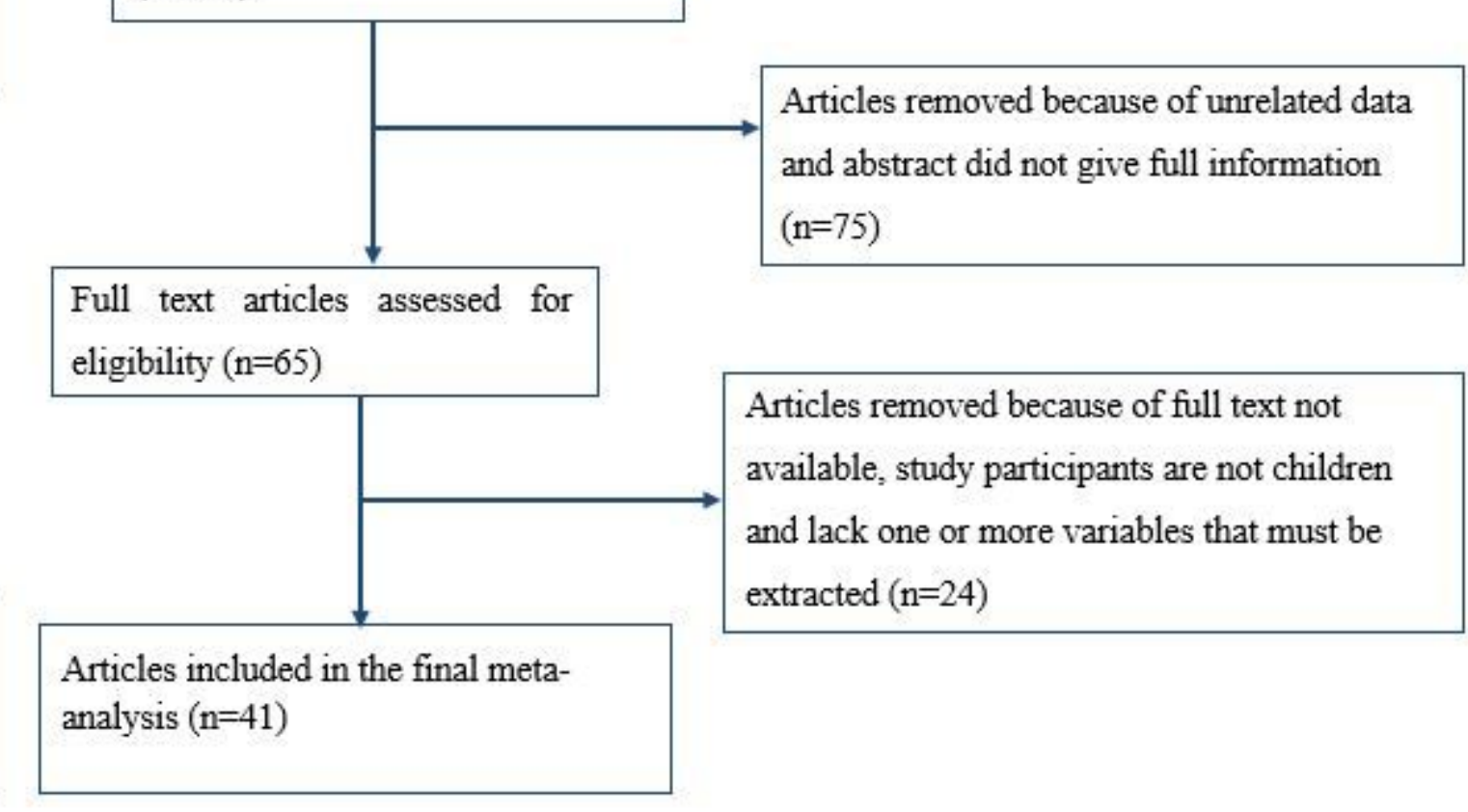

Articles removed because of full text not available, study participants are not children and lack one or more variables that must be extracted $(n=24)$

\section{Figure 1}

Flow chart of selection of studies 


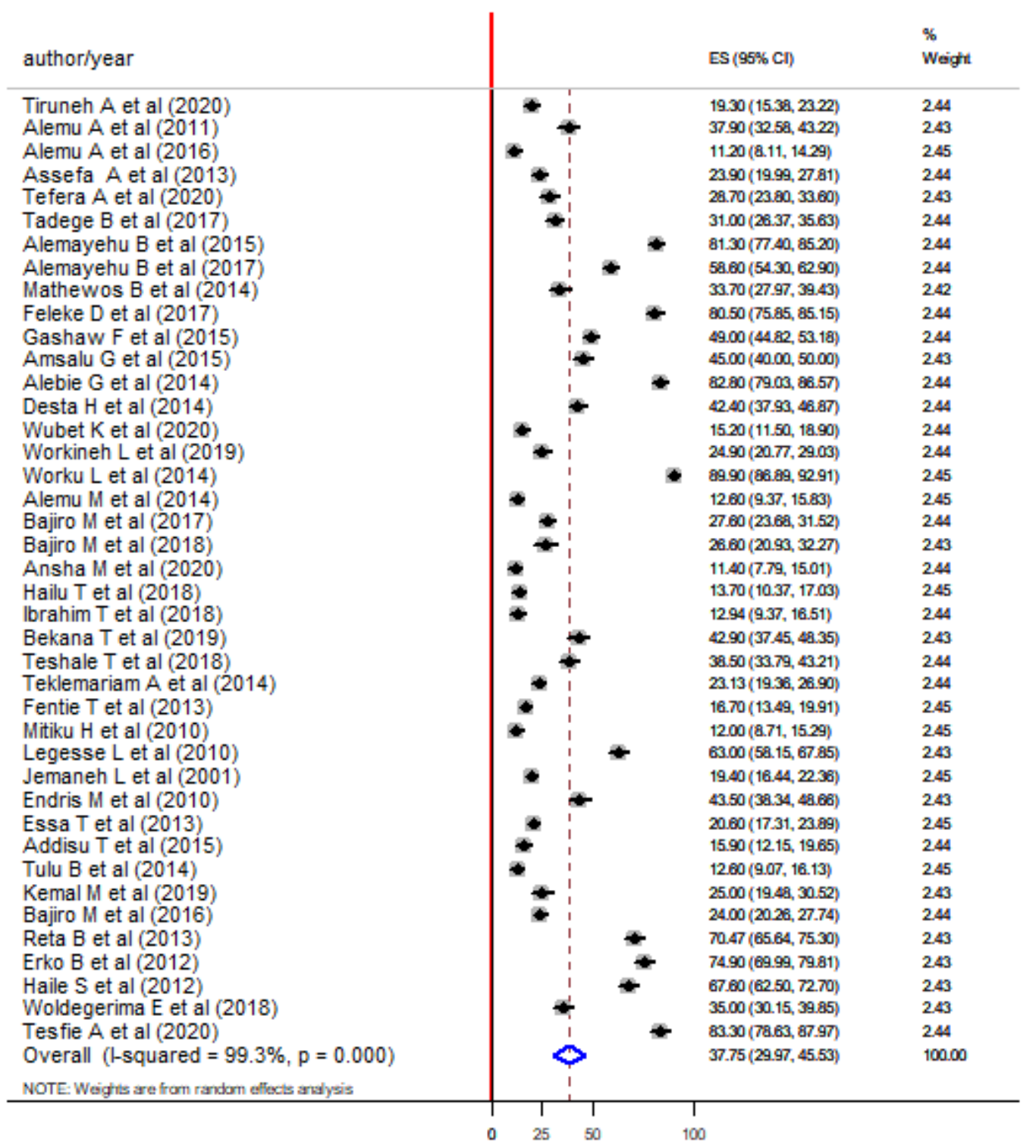

\section{Figure 2}

Forest plot showing the pooled prevalence of Schistosoma mansoni infection among children in Ethiopia. 


\begin{tabular}{|c|c|c|}
\hline author/year & ES ( $95 \%$ CI) & $\begin{array}{l}\% \\
\text { Weight }\end{array}$ \\
\hline 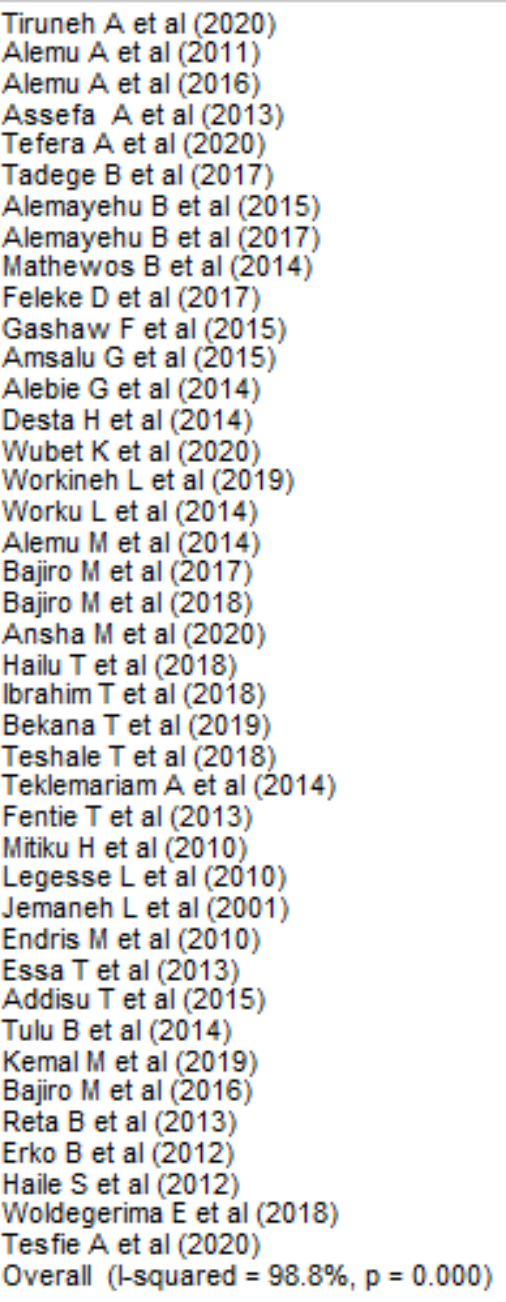 & $\begin{array}{l}26.10(20.00,32.20) \\
33.70(26.31,41.09) \\
12.60(7.79,17.41) \\
30.71(25.18,36.24) \\
39.30(32.46,46.14) \\
31.91(25.95,37.87) \\
85.07(80.14,90.00) \\
62.72(57.13,68.31) \\
28.77(21.24,36.30) \\
17.75(11.99,23.51) \\
59.21(53.18,65.24) \\
53.36(46.58,60.14) \\
83.90(78.63,89.17) \\
50.22(43.72,56.72) \\
15.06(10.32,19.80) \\
29.59(23.61,35.58) \\
90.15(85.07,95.23) \\
17.08(11.98,22.14) \\
28.57(22.83,34.31) \\
29.23(21.41,37.05) \\
8.60(3.96,13.24) \\
20.96(15.11,26.81) \\
14.72(9.77,19.67) \\
51.16(43.69,58.63) \\
5.00(2.24,7.76) \\
27.77(22.24,33.30) \\
19.39(15.31,23.47) \\
13.85(8.86,18.84) \\
70.65(63.74,77.56) \\
22.70(17.81,27.59) \\
49.65(41.57,57.73) \\
18.43(13.99,22.87) \\
19.07(13.22,24.92) \\
17.44(11.77,23.11) \\
27.82(19.63,36.01) \\
25.63(20.08,31.18) \\
78.81(71.06,82.56) \\
78.53(70.32,82.74) \\
29.87(22.87,36.87) \\
42.07(34.92 .49 .22) \\
84.86(79.13,90.19) \\
37.73(29.77,45.68) \\
\end{array}$ & $\begin{array}{l}2.44 \\
2.42 \\
2.45 \\
2.44 \\
2.43 \\
2.44 \\
2.45 \\
2.44 \\
2.42 \\
2.44 \\
2.44 \\
2.43 \\
2.45 \\
2.43 \\
2.45 \\
2.44 \\
2.45 \\
2.45 \\
2.44 \\
2.42 \\
2.45 \\
2.44 \\
2.45 \\
2.42 \\
2.47 \\
2.44 \\
2.46 \\
2.45 \\
2.43 \\
2.45 \\
2.41 \\
2.45 \\
2.44 \\
2.44 \\
2.41 \\
2.44 \\
2.44 \\
2.44 \\
2.43 \\
2.42 \\
2.44 \\
100.00\end{array}$ \\
\hline NOTE: Weights are from random eflects aralysis & & \\
\hline
\end{tabular}

\section{Figure 3}

Forest plot showing pooled estimate of Schistosoma mansoni infection in male. 


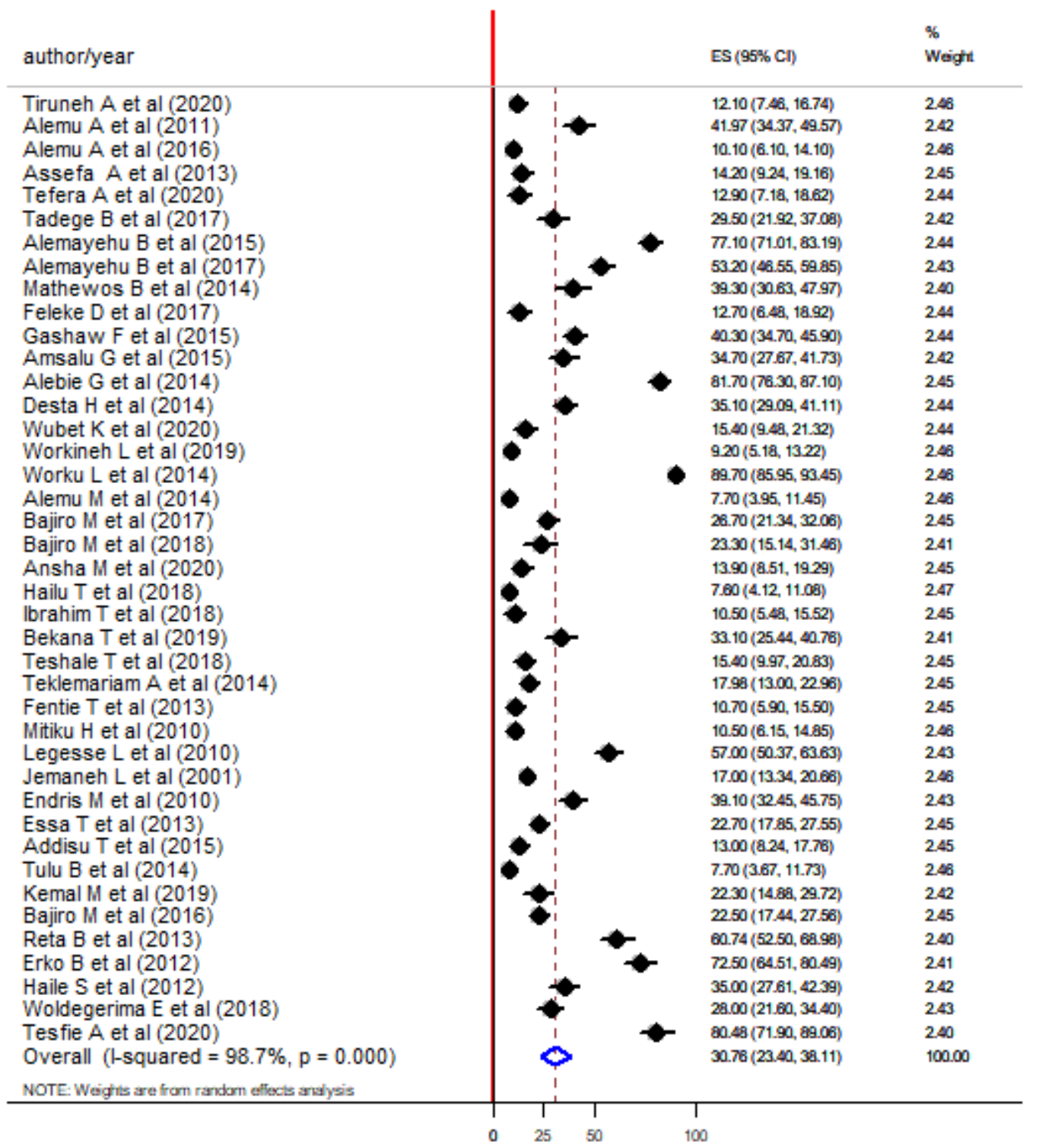

\section{Figure 4}

Forest plot showing pooled estimate of Schistosoma mansoni infection in female.

\section{Supplementary Files}

This is a list of supplementary files associated with this preprint. Click to download.

- PRISMA2009checklist.doc 